\title{
Los vidrios de ciudad de Vascos (Toledo) (ss. X-XI)
}

\author{
Glasses of Ciudad de Vascos (Toledo) (10th-11th C.AD)
}

\author{
Jorge de Juan Ares* \\ Yasmina Cáceres Gutiérrez *
}

\section{RESUMEN}

En este artículo se presenta el estudio tipológico del conjunto de vidrios aparecidos en Ciudad de Vascos (Navalmoralejo, Toledo) (ss. X-XI) depositados en el Museo de Santa Cruz en Toledo (España). En Vascos el vidrio es un material escaso, solo un número limitado de fragmentos han sido recuperados tras cuatro décadas de excavaciones arqueológicas en el yacimiento. A pesar de ello se ha documentado un variado utillaje similar al de otros ajuares andalusíes que incluye vajilla de mesa (vasos, copas, botellas y redomas), elementos de adorno (piedras de anillo y cuentas), perfumería y cuidado personal (sublimadores o ventosas, ungüentarios, ampollas y tapones). En el conjunto es destacable la presencia de vidrios planos decorativos, posiblemente utilizados como decoración arquitectónica. El color de los vidrios varía entre los incoloros, verdes, amarillentos, azules y blancos, pero también están presentes los púrpura-morados. La aparición de fragmentos de vidrio púrpura-morado antecede a otros ejemplos conocidos y plantean la necesidad de reconsiderar la cronología de este tipo de vidrios en al-Andalus.

Palabras clave: Vidrio, al-Andalus, Toledo

\section{INTRODUCCIÓN}

El yacimiento de Ciudad de Vascos constituye uno de los ejemplos mejor conocidos de una pequeña población fronteriza de al-Andalus. Se encuentra situado al sur del Sistema Central en la orilla sur del río Tajo. Un territorio que durante los siglos X y XI se configuró como la frontera entre al-Andalus y los reinos cristianos.

\begin{abstract}
This article presents the typological study of the glass assemblage from the Ciudad de Vascos (Navalmoralejo, Toledo) (10th - 11th century CE) that is now housed in the Museum of Santa Cruz in Toledo (Spain). Glass was evidently scarce at the Ciudad de Vascos. Accordingly, only a limited number of fragments have been recovered during the four decades of archaeological excavations at the site and these include diverse tableware objects (glasses, cups and flasks), ornament elements (ring glass gems and beads), for personal care and perfumery (suction pads or distillers, "toilet bottles" and caps). Remarkable is the presence of decorative flat glasses probably used for architectonical decoration. The colours of the glasses range from colourless, green, yellow, blue and white to deep purple. The deep purple glass fragments from Vascos predate previous Andalusian finds and thus necessitate a reconsideration of the relative chronology of this glass type in al-Andalus.
\end{abstract}

Key words: Glass, al-Andalus, Toledo.

Es un enclave urbano fortificado construido en el siglo X bajo el dominio de la dinastía Omeya, que fue completamente abandonado por su población a finales del siglo XI. Las excavaciones arqueológicas realizadas desde el año 1975 han dado lugar a una amplia bibliografía ${ }^{1}$, convirtiéndolo en un referente sobre la cultura material de este periodo en el centro peninsular.

\footnotetext{
* Chercheur en Archéométrie, Institut de Recherche sur les Archéomatériaux, IRAMAT-CEB (UMR 5060 CNRS), Orleans, Francia.

** Investigadora independiente.

1 La mayor parte de estas publicaciones se encuentran disponibles en: http://www.ciudaddevascos.com/7.\%20CV_Publicaciones. htm [Consulta: 25 de abril de 2016].
} 
En Ciudad de Vascos, el vidrio fue un bien escaso como evidencia el menguado número de ejemplares aparecidos en el transcurso de cuarenta años de excavación. Un hecho que permite apreciar la pobreza material de sus habitantes y la escasa relevancia del enclave en comparación con otros centros urbanos contemporáneos (DE JUAN, 2005: 439-440; Id. 2016: 11-112).

El vidrio en su mayor parte procede de las excavaciones realizadas en la alcazaba y su entorno de estratos datados en la segunda mitad del siglo XI. Acompañando a algunos de los fragmentos que presentamos, se han identificado monedas acuñadas a nombre de al-Mā'mūn de Toledo, al-Mutawakkil de Badajoz, al-Qādiry Alfonso VI (Id. 2016: 219, Fig. 79).

Los vidrios del yacimiento, a pesar de que hasta ahora no han sido objeto de un estudio monográfico, por varios motivos tienen un gran interés. Proceden de contextos estratigráficos bien fechados, situados entre la segunda mitad del siglo $X$ y el último cuarto del XI, en un periodo para el que apenas existen repertorios publicados. En el área geográfica donde se encuentra enclavado el yacimiento apenas se conocen datos sobre el vidrio durante la Edad Media, por lo que aportan una primera referencia para conocer sus características en un periodo cronológico muy bien delimitado, a partir de la cual poder establecer comparaciones con otras localidades más distantes.

En al-Andalus los objetos de vidrio se encuentran presentes en la mayoría de los yacimientos de época andalusí (ss. VIII-XV). Su modesta presencia en los registros arqueológicos en comparación con otro tipo de materiales es probablemente la causa principal de que no hayan sido suficientemente valorados en las investigaciones arqueológicas. Ello ha provocado que nuestro conocimiento sobre vidrio en este periodo sea aún muy limitado (CRESSIER, 2000: 9-10; PUCHE, 2000: 150-151; CARBONI, 2001: 14; JIMENEZ, 2006: 51).

En conjunto se aprecian evidentes similitudes con las formas presentes en otros ajuares andalusíes de diversos ámbitos geográficos (JIMENEZ 1993, PUCHE, 1993; CRESSIER, 2000; VARELA 2003; RONTOMÉ y PASTOR, 2006; CAPELLÀ y RIERA, 2015), mientras que se diferencia nítidamente de las colecciones de vidrios preislámicos del entorno cercano al yacimiento (TORRECILLA, 2004: 323-349). A pesar de estas semejanzas con sus contemporáneos, los vidrios de Vascos presentan algunas características propias con respecto a los repertorios de otras regiones, como la práctica ausencia de hilatura, de grandes redomas - la poca representación del vidrio a molde. Ayudando a precisar la evolución tipológica del vidrio andalusí, gracias a la ausencia de algunas variantes formales típicas de momentos más avanzados de la historia de al-Andalus y a la corroboración de la existencia de otras formas que previamente habían sido datadas en contextos de los siglos X y XI .

Como novedades dentro del panorama andalusí se puede señalar la presencia de un grupo de vidrios de color morado y la documentación de varios tipos formales que hasta ahora no habían sido atestiguados en otros yacimientos.

Por tanto, los vidrios de Ciudad de Vascos contribuyen a ampliar nuestro conocimiento sobre los repertorios producidos y consumidos en las poblaciones de al-Andalus durante los siglos X y XI.

\section{MATERIALES Y METODOLOGIA}

El objetivo de este trabajo es realizar una primera aproximación tipológica a los recipientes de vidrio utilizados en Ciudad de Vascos (Navalmoralejo, Toledo). Se basa en la revisión de todos los vidrios aparecidos en el yacimiento hasta el año 2010.

En primer lugar se han revisado todos los hallazgos vítreos publicados, en total diez ejemplares. Dos procedían del "Barrio de la Era” (IZQUIERDO, 1983: 364, fig. 34, no 6), seis del "Barrio del Portillo" (Id., 1994: 94, fig. 18, no 1-5 y 7; Id. 1999: no 146), y dos de las primeras campañas de excavación realizadas en la alca- 
zaba entre los años 1997 y 1998 (Id., 1999: no 145). A ellos hay que sumar las menciones en otras publicaciones como los dos fragmentos de las "Tenerías" y el aparecido en el "Baño de la Mora" (IZQUIERDO, 1986: 193-242; Id., 1996: 154).

En segundo lugar se ha realizado una revisión de todos aquellos materiales vítreos inéditos que permanecían depositados en el Museo de Santa Cruz (Toledo) ${ }^{2}$. En su mayor parte, ciento setenta y seis fragmentos, proceden de las excavaciones realizadas en la alcazaba entre los años 1996 y 2004 (DE JUAN, 2000: 307-315; IZQUIERDO y DE JUAN, 2003: 423-436; IZQUIERDO, 2008: 269-281; DE JUAN, 2016: 343, Lam. 6). A este grupo hay que añadir los aparecidos en la excavación en torno a la mezquita de barrio localizada al SE de la alcazaba (área 0-4), excavada entre los años 2001 y 2006 (IZQUIERDO Y PRIETO, 1993-94: 21-38; IZQUIERDO Y DE JUAN, 2007: 755-774) que cuenta con una relativa abundancia de fragmentos de vidrio sumando un total de treinta y seis ejemplares. También hay que añadir los seis fragmentos contabilizados en el Área 0-1, a los pies del frente sur de la alcazaba, excavada entre los años 1988 y 1995, cinco fragmentos más aparecidos en la excavación de un sondeo en el basurero situado extramuros al sur de la Puerta Sur en 2006, y los quince aparecidos en las excavaciones de misma puerta y al exterior de la puerta norte desde esa fecha hasta el año 2010.

El análisis de los vidrios ha consistido en su inspección macroscópica en las dependencias del Museo de Santa Cruz, donde se realizó su descripción, dibujo y fotografiado.

Para la descripción de los fragmentos de vidrio se diseñó una ficha que permitiera una catalogación estandarizada e individualizada de las características identificadas en la ins- pección visual. En las fichas se incluyeron los datos necesarios para su identificación espacial, estratigráfica y tipológica. Cuando ello fue posible también se consignó la forma del objeto del que procedía (ungüentario, botella, etc.) y el color del vidrio: verde, morado, amarillento-ambar, azulado, morado, blanco e incoloro, diferenciándose dentro de ellos varias tonalidades. En las fichas también se consignaron otros datos de interés como el diámetro de bordes y fondos, las decoraciones, etc.

Una vez recopilada esta información se realizó un tratamiento estadístico exploratorio y se pudo establecer fácilmente su correlación con la estratigrafía documentada en el yacimiento y con los hallazgos numismáticos identificados en los contextos estratigráficos.

Las ilustraciones que se presentan constituyen una selección de los materiales más significativos del conjunto y solo suponen una parte de todo el material estudiado.

\section{TIPOLOGÍA}

El vidrio fue utilizado principalmente para la elaboración de bisutería y de recipientes pequeños, como demuestra la escasa diferencia entre el número de formas y fragmentos atípicos, y testimonian los únicos recipientes conservados completos: tres ungüentarios (Fig. 2, no 1, 4 y 5) y tres tapones (Fig. 3, no 12-14). Además, a estos usos principales hay que sumar la constatación de la utilización del vidrio como elemento de decoración arquitectónica.

La revisión de los fondos conservados en el Museo de Santa Cruz ha permitido contabilizar un total de 251 elementos vítreos pertenecientes a un máximo de 221 piezas originales ${ }^{3}$. Del

2 Queremos agradecer al director de las excavaciones, Ricardo Izquierdo Benito, así como al personal de la Junta de Comunidades de Castilla-La Mancha y del Museo de Santa Cruz, y en especial a Jaime Gallardo Alamillo y a Jacobo Fernández de Cerro la ayuda prestada en todo momento.

3 Las características del conjunto no han permitido establecer un NMI por lo que hemos optado en esta ocasión por utilizar el criterio de máximo número de individuos. 
total, cincuenta y seis pertenecen a cuentas de material vítreo y joyas para engastar en cabujones y no han sido tenidos en cuenta para este trabajo. Su descripción pormenorizada y tipología serán objeto de una próxima publicación.

Del conjunto de vidrios tan solo en setenta y siete casos, un $34 \%$, han podido establecerse inferencias sobre los recipientes de los que procedían. En total se han contabilizado treinta y ocho fondos, treinta y tres bordes, tres asas y casi dos decenas de vidrios planos.

La cantidad de fragmentos es muy reducida si tenemos en cuenta que proceden de cuarenta años de campañas arqueológicas entre los años 1975 y 2010. A pesar de ello, se puede identificar una cierta variedad tipológica.

Entre los objetos más representativos se encuentran los fragmentos de tubos-ungüentario de fondo plano, convexo o con umbo, las ampollas y los tapones.

De forma más ocasional aparecen otras formas como copas, vasos, botellas o redomas. Los fragmentos de vidrio plano también se encuentran presentes y probablemente fueron utilizados como decoración arquitectónica.

Distintas publicaciones han permitido ampliar el repertorio formal del vidrio andalusí respecto a lo conocido hace quince años. Un conjunto de variados e interesantes trabajos han dado a conocer nuevos materiales procedentes de contextos arqueológicos. Sin embargo, en la actualidad no existe una tipología de referencia de los vidrios del periodo andalusí. Por lo que nos remitiremos a paralelos de otras publicaciones y puntualmente, para describir algunas formas completas, a los tipos establecidos por Isings para el vidrio romano (ISINGS, 1957).

\section{Ungüentarios}

Son formas cerradas de pequeño tamaño destinadas a contener ungüentos o perfumes. Pueden dividirse en dos grupos: tubos y ampollas.

\section{Tubos}

Tienen forma alargada con fondos de pequeño diámetro prolongados en un cuerpo tubular. No se ha conservado ningún ejemplar completo, encontrándose representado principalmente por fragmentos de bases a las que se asociarían bordes moldeados en caliente. Esta forma de rematar las piezas se evidencia también en los restos de puntel (Fig. 1, n 11, $12,21,23)$ o en su impronta en la base de los recipientes.

Se pueden distinguir varios grupos de bases: las bases más o menos planas (Fig. 1, no 13-16), los fondos cóncavos (Fig. 1, n 18, 20, 22-24), los umbos suaves (Fig. 1, no 10, 17, 19) $y$, de forma más esporádica, las bases apuntadas o con un pequeño botón (Fig. 2, no 19). No resulta descabellado pensar que alguno de estos fondos tubulares pudiera corresponderse con el remate de una lámpara, pero la simetría y verticalidad general de sus paredes parecen descartarlo (CASTILLO, 2000: 140).

Este tipo de ungüentarios tienen una amplia dispersión geográfica y perduración temporal, estando presentes tanto en el siglo X y XI en Sant Menna (Barcelona) (COLL, 2004: 451 y fig. 2) o en Baŷŷāna (Almería) (CASTILLO y MARTINEZ, 2000: 95, Fig. 4.8), como en el siglo XIII en Aspe (PUCHE, 2000: 162, Fig. 1, no 7 y 8) o en la Cova dels Amagatalls (CAPELLÀ y RIERA, 2015: Fig. 4.3).

Dentro de este grupo de ungüentarios hay que destacar la aparición de un tipo especial del que se conocen dos ejemplares casi completos y varios fragmentos. Se trata de un tipo hasta ahora no descrito en el repertorio andalusí. Son ungüentarios tubulares decorados con tiras de vidrio aplicadas y pinzadas en caliente a lo largo de la pieza formando gallones que se disponen longitudinalmente. En el ejemplar de menor tamaño las tiras laterales se prolongan a modo de pies, mientras que el más grande presenta fondo plano (Fig. 3, n० 5 y 6). Las decoraciones pinzadas a lo largo de la pieza son un recurso utilizado desde época romana con pocos ejemplos conocidos en alAndalus (CAPELLÀ y RIERA, 2015: 315-316, Fig. 
2.8), aunque bien documentadas en oriente (BERNUS-TAYLOR, 2000: Fig. 2.3).

Sobre los removedores que pudieran asociarse a este tipo de ungüentarios solo puede apuntarse la aparición de un fragmento pequeño de una varilla cilíndrica de color verdoso. Sin embargo, hay que señalar cierta tendencia a la aparición en los mismos contextos de fragmentos de fondos de ungüentarios con cucharillas de bronce y varillas de asa de presión central (IZQUIERDO, 1994: 159). Una asociación que apunta la posibilidad de una relación estrecha entre ambos tipos de objetos como se documenta, para época romana, entre los removedores de bronce o vidrio y los ungüentarios olliformes (ISINGS, 1957: 88).

\section{Ampollas}

Son recipientes de pequeño tamaño con cuello exvasado y estrecho.

En Vascos se encuentran presentes dos variantes. Una de cuello alto y cuerpo tubular, cuya parte inferior puede confundirse fácilmente con ungüentarios tubulares. Otra, de cuello corto y cuerpo globular que a veces son denominadas "botellitas" en la bibliografía.

Del primer tipo conocemos varios fragmentos de bordes exvasados con labios cortados y suavizados al fuego (Fig. 1, no 2-9), uno de ellos decorado con líneas incisas horizontales (Fig. 1, no 2). Ampollas similares de borde exvasado, fondo cóncavo y paredes gruesas se han documentado en Alicante y Mallorca en contextos del siglo XII (PUCHE, 1993: 929-930, Fig. 1.21, Id, 2000: 160, Fig. 1.4-5; CAPELLÀ y RIERA, 2015: 318, Fig. 4.3.8). Dado el reducido tamaño de los fragmentos de borde no puede excluirse que alguno pueda corresponderse con pequeñas botellas o incluso platos ${ }^{4}$.

Al segundo grupo, peor definido, podrían corresponderse algunos bordes de pequeñas ampollas (Fig. 1, no 1 ) a las que presumible- mente se sumarían bases con umbo, tal vez con formas similares a las de Lietor (Albacete) fechadas a fines del siglo X o comienzos del XI (NAVARRO y ROBLES, 1996: 79-80).

\section{Olliformes}

A este grupo de ungüentarios se adscriben dos recipientes completos y algunos fragmentados que permiten distinguir dos variantes.

La primera es asimilable formalmente al grupo de ungüentarios de tradición romana Ising 68, denominado ungüentario olliforme por su parecido con una olla de pequeño tamaño (Fig. 2, no 4). Los ejemplares de Vascos se diferencian de los ejemplares romanos por la presencia de un umbo en su base (SALINAS, 2003: 64, Fig. 7.55).

La segunda variante también presenta umbo y carece de paralelos bien contextualizados. El único ejemplar conservado intacto se encontró embutido en el interior de un muro situado en la parte más oriental de la alcazaba (Fig. 2, n 5). La construcción del muro puede fecharse entre la segunda mitad y el último cuarto del siglo XI, a partir de la estratigrafía y los hallazgos numismáticos (DE JUAN, 2016: 313-314). Presenta una cuidada factura con un fino borde exvasado de cuello largo con un hombro saliente marcado y base con umbo.

\section{Ungüentarios de cuello largo y estrecho}

En todos los casos se trata de recipientes de pequeño tamaño con cuello alto y base engrosada. Se distinguen dos variantes.

La primera son ungüentarios globulares de cuello alto de los que se conocen dos ejemplares. El primero tiene forma globular de base aplanada. Tienen una coloración oscura, casi negra, y no conserva el borde (Fig. 2, no 3). El segundo es un pequeño ungüentario completo de factura más irregular, borde doblado y base ligeramente cóncava (Fig. 2, nº

\footnotetext{
4 Recordar la dificultad que en los fragmentos pequeños de vidrio tiene en muchas ocasiones reconocer la orientación correcta de las piezas, por la irregularidad de algunos bordes y la inexistencia de huellas de torno como en el caso de la cerámica.
} 
1). Ejemplares de forma similar, en este caso con umbo y de mayor tamaño han aparecido en Casa Herrera (Badajoz), fechados entre los siglos VI y VII (GAMO: 304, Fig. 2.5). Las concreciones que los recubren impiden conocer por el momento sus colores originales.

Un segundo grupo son los ungüentarios piriformes. Se ha conservado casi completo un único ejemplar que no conserva el borde. Está realizado con un vidrio de color verde claro y presenta un característico umbo central en su base (Fig. 2, n²).

\section{Botellas, redomas y jarras}

Se engloban dentro de este grupo formas cerradas de tamaño mediano con cuello y cuerpo esférico, cilíndrico o prismático. No se han documentado recipientes completos, pero si algunos fragmentos que por sus características se encuadrarían en este tipo de recipientes. Los bordes incluidos en este amplio grupo no se corresponden por su forma y tamaño con ungüentarios, caracterizándose por ser muy exvasados (Fig. 2, no 6-8, 10 y 14). Los fondos por su parte tienen un umbo más o menos marcado (Fig. 2, no 15-17). A partir de los restos conservados resulta imposible restituir su forma original aunque en ellos se reconocen botellas, redomas y jarras como las documentadas en otros yacimientos peninsulares.

Se han localizado fragmentos de pequeñas asas que también cabría incluir en este grupo, que formarían parte de jarritas de pequeño tamaño (Fig. 3, no 8 y 10).

En el conjunto de piezas solamente se ha identificado un fragmento decorado (Fig. 3 , no11). Se trata de una base de redoma de vidrio amarillento soplada a molde con decoración de pequeños losanges irregulares que recubren toda la pieza. Se recuperó en un contexto estratigráfico fechado entre la segunda mitad y el último cuarto del siglo XI. Gómez Moreno denominó a esta decoración "granos de cebada", considerándola una producción local de Madinnat al-Zahrā' (GOMEZ-MORENO, 1951: 344; RONTOME, 2000: 111, Fig. 2.3). Se trata de un tipo de ornamentación similar a la de los ejemplos murcianos fechados entre mediados del siglo IX y los primeros decenios del X (GUTIERREZ, 1996: Fig. 90.3), siendo habitual en otros yacimientos del periodo andalusí (JIMENEZ, 2000: Fig. 7. 1 y 3-7; PUCHE, 2000: Fig. 1. 2-3; RONTOMÉ y PASTOR, 2006: no 5-7; CAPELLÀ y RIERA, 2015: Fig. 1.5).

\section{Copas}

En el conjunto de vidrios recuperados en Ciudad de Vascos solo ha sido posible identificar cuatro fragmentos de copas. Su mal estado de conservación impide la restitución de su forma original.

La primera es un pie de cinco centímetros de diámetro con labio redondeado y lo que parece son los restos de una decoración plástica alrededor de la base (Fig. 2, no 22). La segunda pertenecía a un tipo totalmente distinto. De ella tan solo se ha conservado un fragmento de fondo plano modulado del que arrancaría un fuste macizo (Fig. 2, no 21). La tercera copa es la que tiene un mayor tamaño (Fig. 2, no 23). De ella se ha conservado el borde de una base con moldura simple y un diámetro de 8,2 centímetros con el labio roto. Presenta una inflexión cercana al pomo a modo de hombro. De las copas restantes tan solo se han conservado sus fustes de sección circular (Fig. 3, no 7 y 9).

Este tipo de formas para beber parecen gozar de una mejor representación en el periodo visigodo precedente y en las áreas de dominio cristiano (GAMO, 2010: 482-483), siendo poco frecuentes en los contextos andalusíes donde solo se documentan esporádicamente fragmentos de fuste o pies y muy rara vez alguna pieza completa (VARELA, 2003: 210, Fig. 175; CAPELLÀ y RIERA, 2015: 314, Fig. 2.7; RONTOMÉ y PASTOR, 2006: no 8-12 y 61).

\section{Vasos}

Los ejemplos documentados son recipientes troncocónicos invertidos de fondo plano. Solo se han conservado fragmentos de paredes y una única base que pueda adscribirse 
a este grupo (Fig. 2, no 18). En todo caso no puede descartarse que algunos de los fragmentos de fondo considerados de redomas o botellas pudieran pertenecer a vasos de paredes lisas.

A diferencia de las copas, los vasos se encuentran bien representados en las publicaciones para todo el periodo andalusí. En este caso se conoce una variada tipología que abarca desde la época omeya al periodo nazarí (DE JUAN Y CÁCERES, 2016; CASTILLO, 2000: 134-136; RONTOMÉ, 2000: 104; RONTOMÉ y PASTOR, 2006: 6-7, 40-51, 57-59, 62, 65, 72, 75 y 92).

Esta abundancia de vasos frente a la escasa representación de las copas plantea la posibilidad de la vigencia de ciertos prejuicios culturales (asimilación a la eucaristía cristiana, a la monarquía y al consumo de vino). Prueba de ellos serían, en el siglo XII, las palabras de Ibn 'Abdun cuando en su tratado de hisba indica que: "deberá de prohibirse a los vidrieros que fabriquen copas destinadas al vino", siendo consideradas por tanto como harām (ALMAGRO y ALONSO, 2009: 201; CASTILLO, 2006: 53; GARCÍA GOMEZ y LEVÍ-PROVENÇAL, 1981: 136-137), aunque el vino nunca dejará de consumirse (MARTíNEZ y BELLÓN, 2005).

\section{Lámparas}

Entre el repertorio de vidrios recuperados en las excavaciones de Ciudad de Vascos no contamos con ejemplos claramente atribuibles a lámparas, toda vez que los remates tubulares parecen corresponderse en todos los casos con ungüentarios. Tal vez pudieron pertenecer a lámparas algunos fondos apuntados o con botón (Fig. 2, no 19 y 20), aunque su estado fragmentario, y los pocos y tardíos paralelos impiden afirmarlo con seguridad (PUCHE, 1993: 930, Fig. 24-27; VARELA, 2003: 210, Fig. 135; GARCÍA, 2009).

\section{Tapones}

Los tapones no superan los dos centímetros de diámetro. De ellos contamos con varios ejemplares, todos con borde remar- cado al exterior modelado al fuego (Fig. 3, no 12-14). Hay que suponer que se asociarían a los distintos tipos de ungüentarios presentes en el yacimiento. Aunque los bordes de estos recipientes suelen tener un diámetro mayor.

La asociación de los tapones con los ungüentarios tubulares parece confirmarse en al menos un caso (Fig. 3, no 13). Apareció en la excavación de una cocina junto a un fondo de ungüentario tubular de base plana y paredes finas (Fig. 1, n 20) (IZQUIERDO, 1994: 22, Fig. 18, 7).

Existen paralelos para este tipo de piezas desde época romana, algunos de cuerpo macizo (SALINAS 2003: 105, Fig. 163), siendo pocos los publicados de momento para el periodo andalusí como los aparecidos en Calatrava entre finales del siglo XII e inicios del siglo XIII (RONTOMÉ y PASTOR, 2006: no 24-27). En este caso presentan unas alas más desarrolladas respecto al cuerpo y una forma ligeramente apuntada. Por su parte los ejemplares de Ciudad de Vascos se documentaron en contextos bien datados de la segunda mitad del S. XI. Es probable que en algunos casos estos ungüentarios tuvieran tapones de corcho como se documenta en un ungüentario de similar cronología procedente de Albarracín (PEREZ-ARANTEGUI, 2015: 714).

\section{Alambique o ventosa}

Entre los materiales vítreos recuperados en las excavaciones de Ciudad de Vascos se ha localizado un único fragmento que podría ser identificado bien como parte de un alambique o como una ventosa. Formaría parte de un recipiente de color verde esmeralda con un extremo cónico alargado que se estrecha progresivamente y un lado más ancho con un pequeño hombro que parece indicar el punto de unión con un cuerpo más globular (Fig. 3, no 15).

Una pieza muy parecida fechada en el siglo IX apareció en el nivel I de Baŷŷāna donde es interpretada como alambique o sublimador de perfumes (CASTILLO y MARTINEZ, 2000: 97, Fig. 5. 5). A un tipo diferente corresponde- 
rían los ejemplares publicados para Madinat al-Zahrā' (RONTOMÉ y PASTOR, 2006: n 34). En este caso son interpretados como alambiques o sublimadores exclusivamente cuando su pipa o cañón apunta hacia abajo y, en caso contrario, como ventosas curativas similares a las representadas en algunas miniaturas árabes (RONTOMÉ, 2000: 110).

\section{Vidrio arquitectónico}

En el conjunto de vidrios de Ciudad de Vascos aparecen con relativa frecuencia pequeños fragmentos de vidrio plano que cuentan por lo general con menos de un milímetro de espesor y cortes rectos (Fig. 3, no 1-4). No parecen asociarse a ningún recipiente concreto. Su reducido número y dimensiones no permiten de momento establecer conjeturas sobre su utilidad. Sin embargo, en el conjunto de vidrios existen dos ejemplares que podemos interpretar con bastante seguridad como vidrios de uso decorativo.

Un primer fragmento, más o menos plano, es un vidrio reutilizado recortado intencionadamente en forma de círculo de $22 \mathrm{~mm}$ de diámetro (Fig. 3, no 3). Como hemos podido comprobar en los fondos del Museo de Santa Cruz, existe un ejemplo de similar tipología, ligeramente más grande, procedente de las yeserías del palacio de al-Ma'mun en Toledo (1044-1075) (MONZÓN y MARTíN, 2006, 66-72; GONZALEZ, 2014: 196, 210-213). Además de la forma, su posible uso decorativo parece avalado por haber aparecido sobre el suelo y bajo los restos de la cubierta de la mezquita de la alcazaba de Vascos (DE JUAN y CÁCERES, 2010; DE JUAN, 2016: 197-213, 219).

El segundo objeto es una plaquita de vidrio completa que se encuentra fragmentada en dos mitades. Apareció en el patio de un edificio situado a los pies de la mezquita. Tiene una forma cuadrada de bordes achaflanados en forma de octógono regular, contando con las mismas dimensiones que el ejemplar anterior (Fig. 3, no 4). No conocemos para al-Andalus ejemplos de piezas de similar cronología, aunque podría relacionarse con los espejitos y otras formas poligonales similares a las citadas para el Convento de Santa Fe o, para contextos más tardíos de finales del siglo XII y principios del XIII, en Yecla y Siyāsa (NAVARRO y CASTILLO, 2002: 65; 2009: 484; RUIZ, 2000: 163-164).

\section{COLORES}

La inspección visual solo ha permitido identificar el color del vidrio en menos de la mitad de los fragmentos recuperados en las excavaciones: un total de ciento veintisiete. En la tabla 1 se muestran las proporciones de colores de vidrio reconocibles en Ciudad de Vascos.

El tipo de vidrio más abundante es el incoloro, algo que es infrecuente en los repertorios tardoantiguos. Algo menor, pero también elevada es la proporción de vidrios de coloración verde. En un tercer grupo, con porcentajes cercanos al $15 \%$ se encontrarían los vidrios de color morado-purpura y azules de distintas tonalidades. Algo menos de la mitad suponen los ámbar y amarillentos (claros y oscuros), contando los blancos opacos con una presencia anecdótica.

\begin{tabular}{|l|r|r|}
\hline \multicolumn{3}{|l|}{ COLOR DEL VIDRIO } \\
\hline Verde claro & 30 & $23,62 \%$ \\
\hline Verde oscuro & 2 & $1,57 \%$ \\
\hline Incoloro & 44 & $34,64 \%$ \\
\hline Amarillento-ámbar & 9 & $7,08 \%$ \\
\hline Blanco & 2 & $1,57 \%$ \\
\hline Azul claro & 19 & $14,96 \%$ \\
\hline Azul oscuro & 3 & $2,36 \%$ \\
\hline Púrpura & 18 & $14,17 \%$ \\
\hline TOTALES & 127 & $99.7 \%$ \\
\hline
\end{tabular}

Tabla 1. Colores del vidrio en Ciudad de Vascos

En el conjunto resulta llamativa la abundancia un vidrio de color morado-púrpura empleado en la fabricación de algunas piezas. En este caso existe una asociación reiterada entre los vidrios de este color y los ungüentarios tubulares, aunque también es utilizado en otros objetos como botellas o redomas. Vidrios con semejantes colores son conocidos desde la antigüedad. Para al-Andalus se ha 


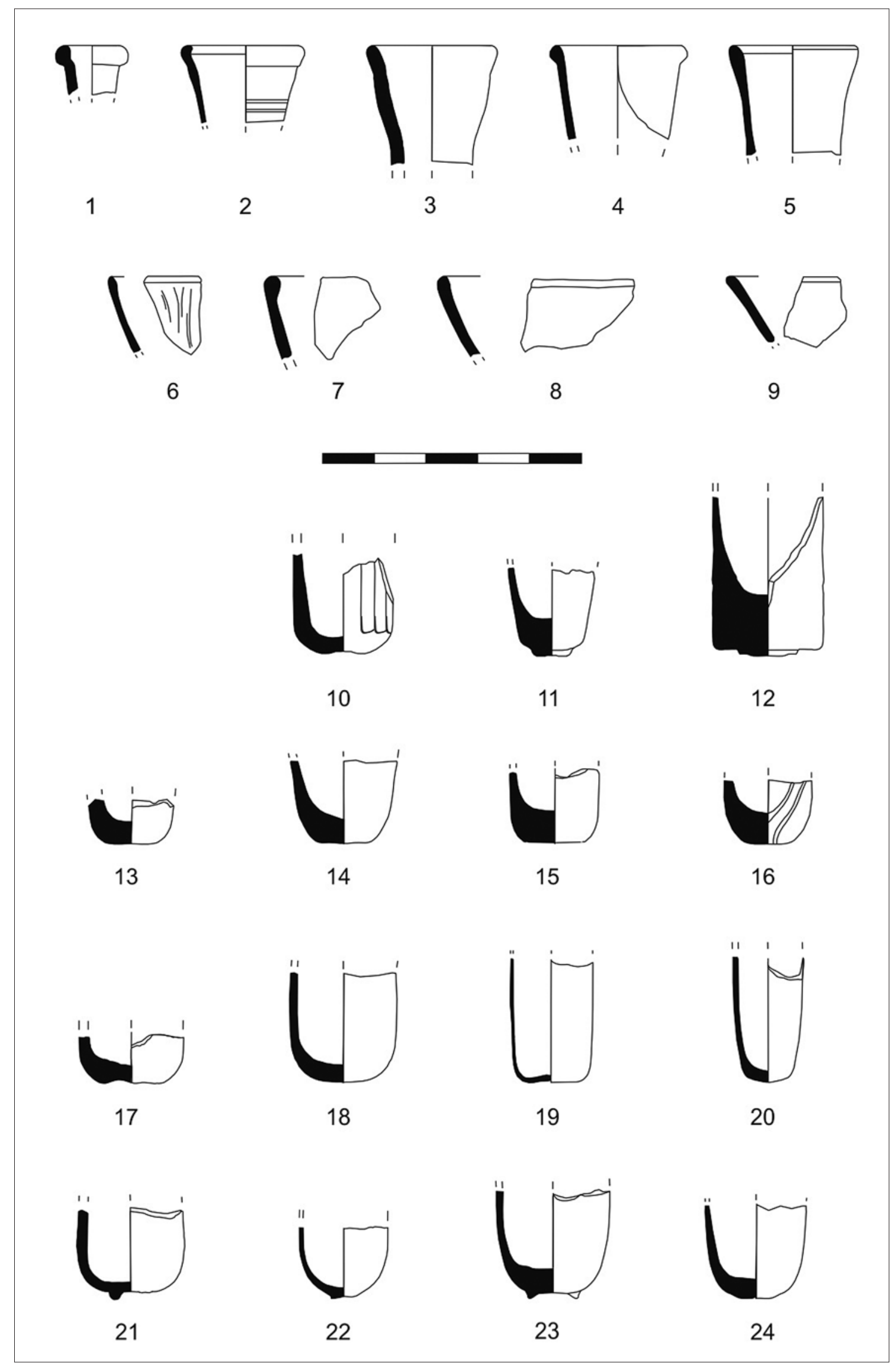

Fig. 1. Bordes y bases de ungüentarios. 


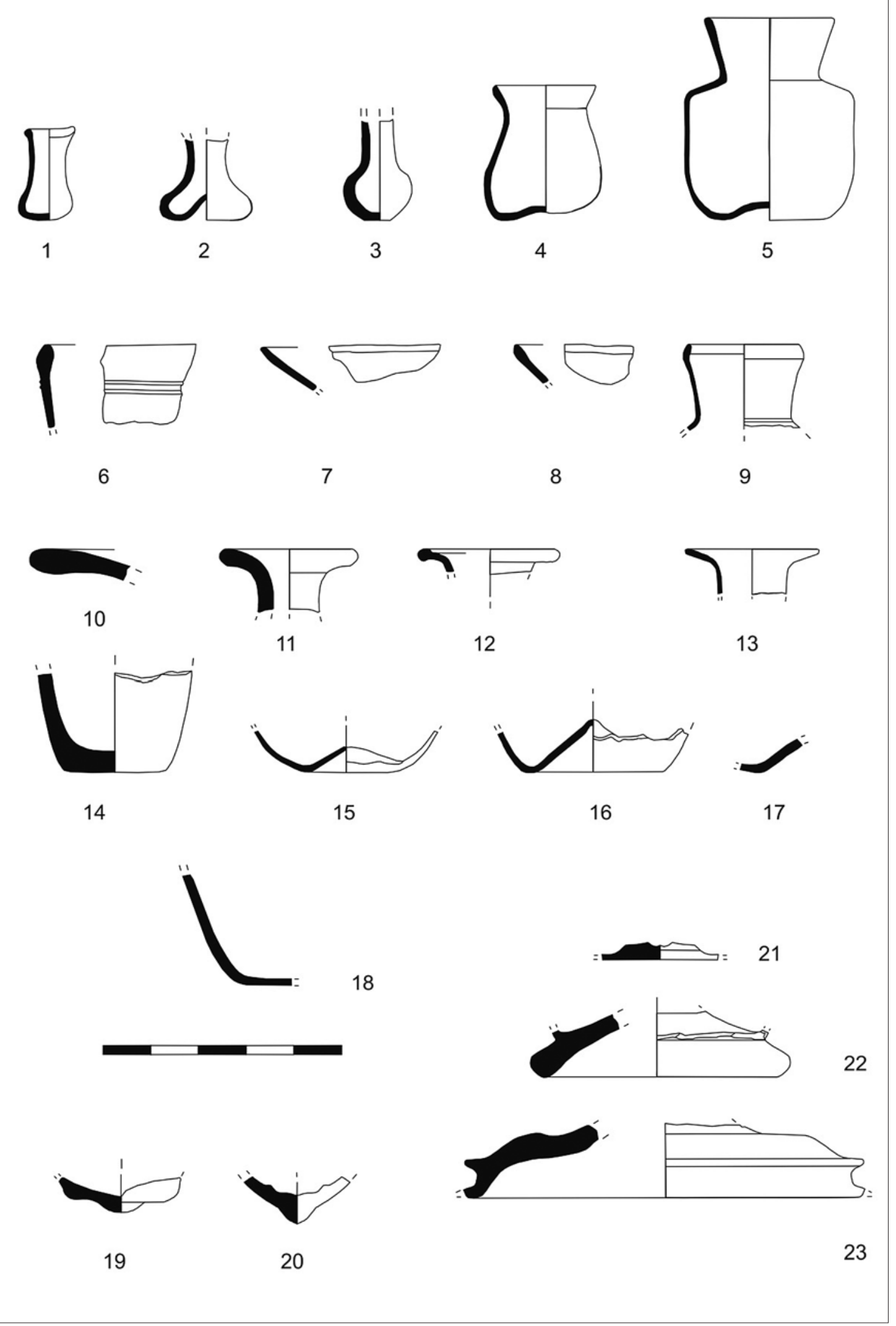

Fig. 2. Ungüentarios, botellas, jarras, copas y redomas. 

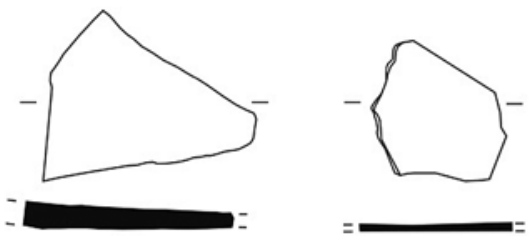

1

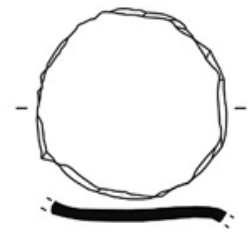

3

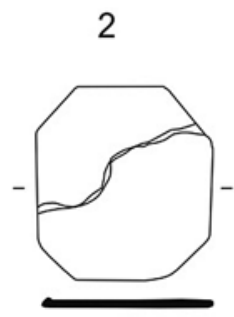

4
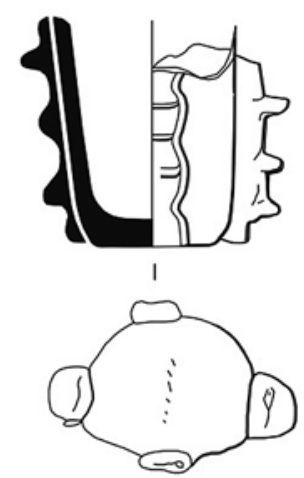

5

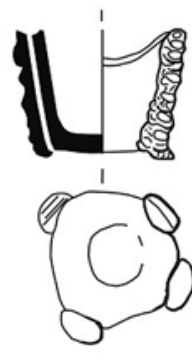

6
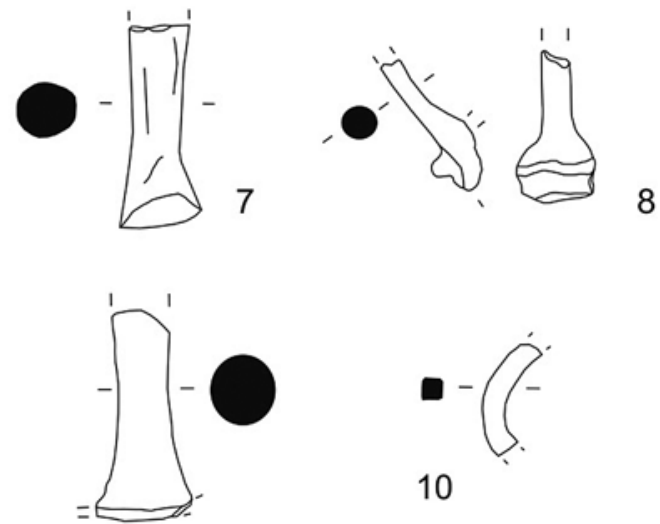<smiles>Cc1ccccc1</smiles>

10

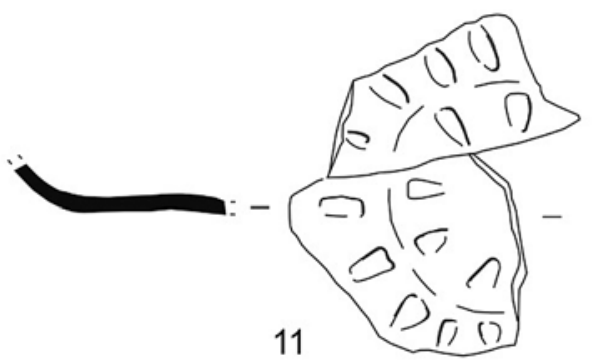

9

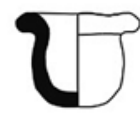

12

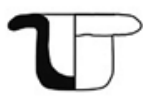

13

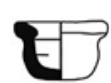

14

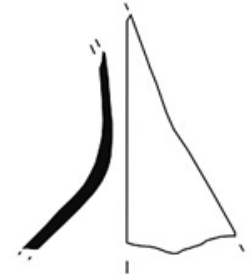

15
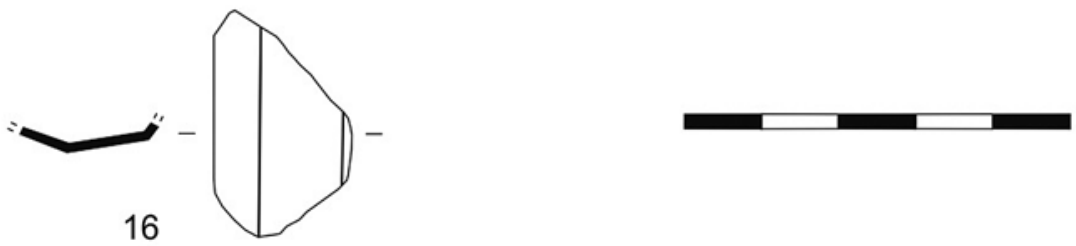

Fig. 3. Vidrios decorativos, tapones, soplados a molde, ungüentarios con decoración aplicada y asas. 
considerado que los vidrios de esta coloración solo estarían presentes en contextos tardíos a partir de los siglos XII y XIII (ZOZAYA, 2000: 79; ALMAGRO y ALONSO, 200: 2009; CARMONA et al., 2008: 75-77), con un periodo de esplendor desde finales de la Edad Media hasta mediados del XVI (FERNANDEZ, 1991: 498-499).

Los vidrios de Vascos proceden de contextos estratigráficos bien datados en la última fase de ocupación islámica de la segunda mitad del siglo XI y, en algún caso, de estratos inmediatamente posteriores a la conquista castellana de Toledo en 1085 (DE JUAN, 2016: 313-314). Distintos hallazgos arqueológicos están demostrando que esta coloración, semejante a la de algunos vidrios de las yeserías del Convento de Santa Fe de Toledo (GONZALEZ, 2014: 210-211), se encontraría presente en al-Andalus desde fechas más tempranas. La cronología de los vidrios morado-púrpura de Vascos, de la segunda mitad del siglo XI, los convierte en los más antiguos conocidos de este tipo entre los hasta ahora documentados en contexto estratigráfico en al-Andalus.

\section{TÉCNICAS}

A excepción de las piezas de joyería, los vidrios de Ciudad de Vascos fueron soplados al aire con tres únicos casos soplados a molde (Fig. 1 no 10 y Fig. 3, no 11 y 16). Tan solo ha sido posible identificar un fragmento muy dudoso de vidrio "en corona".

Los vidrios Ciudad de Vascos presentan un repertorio ornamental limitado. Entre las muestras catalogadas se han identificado dos piezas decoradas a molde. La primera es una base de redoma con decoración de "grano de cebada" (Fig. 3, no 11). Esta forma de ornamentación de origen romano es frecuente en contextos andalusíes fechados entre los siglos X y XIII (CRESSIER, 2000; RONTOMÉ y PASTOR, 2006; CAPELLA, 2015: Fig. 4.2).

La segunda pieza es un ungüentario tubular con acanaladuras longitudinales a lo largo del cuerpo (Fig. 1, no 10). Una decoración que parece haber gozado de cierta difusión como parece indicar un ungüentario tubular procedente de Mallorca fechado en el siglo XIII (CAPELLA y RIERA: 317, Fig. 4.4).

Entre el resto de decoraciones ya hemos mencionado las plásticas aplicadas y pinzadas sobre las paredes y las bases de pequeños ungüentarios tubulares (Fig. 3, no 5 y 6). Las decoraciones pinzadas cuentan por el momento con pocos ejemplos en al-Andalus (VARELA, 2003: 213-215; RONTOMÉ y PASTOR, 2006: 136-137; CAPELLÀ y RIERA, 2015: Fig. 2.8),

De manera más restringida aparecen decoraciones como la hilatura, presente en un borde decorado con hilos blancos horizontales aplicados y fundidos con el cuerpo de la pieza (Fig. 2, n 6). La decoración de hilatura aplicada de tradición romana es frecuente en el vidrio islámico. En las producciones andalusíes tempranas se encuentra poco representada, pero parece alcanzar mayor difusión a partir de finales del siglo XII. El fragmento de vidrio de Vascos presenta la particularidad de que los hilos de vidrio blanco aplicados fueron incrustados en el cuerpo de la pieza aún en caliente. Una técnica poco habitual en alAndalus, máxime en una época tan temprana. Se conocen piezas con similar tipo de decoración de hilos blancos incrustados en el borde en yacimientos carolingios datados entre los siglos IX y X (GRATUZE et al., 2014: 114-116).

Otro tipo de decoraciones, como las incisas, resultan más difíciles de identificar por el reducido tamaño de los fragmentos conservados (Fig. 1, no 2 y 16; Fig. 2, no 9).

La existencia de vidrios pintados no puede ser descartada a partir de las evidencias disponibles. Sin embargo el estado de conservación de algunos vidrios impide asegurarlo sin la realización de analíticas y de un trabajo de restauración y limpieza.

\section{VALORACIÓN Y PERSPECTIVAS}

Incluso cuando el número de fragmentos recuperados en cuarenta años de excavaciones no es cuantitativamente muy abundan- 
te, la investigación realizada ha permitido identificar un variado repertorio de objetos que abarcan un amplio abanico funcional, incluyendo la vajilla de mesa (vasos, copas, botellas, redomas); la joyería (piedras de anillo, cuentas), los objetos de perfumería y médicos (ungüentarios, ampollas, tapones y ventosas o sublimadores), e incluso vidrio arquitectónico. En el conjunto se aprecia una cierta homogeneidad en los tipos con un predominio de los recipientes de pequeño tamaño, especialmente de los ungüentarios.

El limitado número de fragmentos de vidrio, su uso en joyería y adornos, así como su mayor abundancia en los estratos excavados en la alcazaba y su entorno, indican que se trataba de un material lujoso. En Vascos el vidrio sería un bien escaso, tal vez solo al alcance de las clases más pudientes.

A la escasez de objetos hay que unir la inexistencia de restos que puedan hacer sospechar la presencia de talleres dedicados a su fabricación o transformación. Por todo ello hay que interpretar que el vidrio era importado de otros lugares en forma de objetos ya acabados.

Un hecho relevante es la constatación, al igual que con otros restos arqueológicos de pequeño tamaño, que la metodología determina las posibilidades de detectar vidrio durante el proceso de excavación. Una apreciación que resulta evidente cuando constatamos que en todas las ocasiones en que se ha cribado el sedimento, como en los basureros, han sido varios los fragmentos de vidrio localizados. Mientras que su número sigue siendo muy reducido para el conjunto de la superficie excavada. Por tanto, solo el cribado del sedimento garantiza la documentación de los vidrios presentes en un estrato.

Respecto a los colores del vidrio en más de la mitad de la muestra predominan los verdes de variadas tonalidades. Los vidrios incoloros denotarían un mayor control en la selección de los materiales. Los vidrios morados aparecen en una proporción similar a los ambarinos o amarillentos frecuentes en los repertorios de la antigüedad tardía. Mientras que por el contrario son muy escasos los vidrios de color azul o blanco. Los fragmentos de vidrio morado de Vascos anteceden a otros ejemplos previamente conocidos y plantean la necesidad de reconsiderar la cronología hasta ahora establecida para este tipo de vidrios en al-Andalus.

Los vidrios se concentran en zonas concretas del yacimiento como la alcazaba. La distribución espacial de los fragmentos denota asociaciones significativas que serán tratadas con mayor detalle en otros trabajos. El análisis de estas asociaciones podrá aportar en un futuro nuevos elementos que ayuden a clarificar la funcionalidad de algunos recintos habitacionales y el uso de los elementos de vidrio en ellos utilizados.

Por su parte, las técnicas arqueométricas están permitiendo grandes avances en el estudio del vidrio. Los análisis de contenidos orgánicos o minerales han evidenciado el uso de los ungüentarios como contenedores de aceites, polvos cosméticos y perfumes (PEREZARANTEGUI, 2015).

Desde el punto de vista de su composición, son todavía pocos los análisis químicos de vidrios de al-Andalus (GONZALEZ, 2014: 212-213; CARMONA et al., 2008 y 2009; DUCKWORTH et al., 2015). Sin embargo para otros periodos y entornos geográficos, el análisis de la composición química se ha revelado como un medio fiable y eficaz de investigar la evolución tecnológica, el origen de las materias primas y discernir entre los distintos centros productores de vidrio. Ello ha abierto nuevas posibilidades para el estudio de la tecnología, la economía y las redes comerciales medievales a corta y larga distancia que esperamos en un futuro sirvan para ampliar nuestro conocimiento sobre el vidrio andalusí ${ }^{5}$.

5 En el momento de escribir estas líneas se está realizando un muestreo de los vidrios de Ciudad de Vascos depositados en el Museo de Santa Cruz de Toledo para su caracterización química en Institut de recherche sur les archéomatériaux (IRAMAT-CEB, UMR 5060) de Orleans, cuyos resultados serán interpretados y dados a conocer en próximas publicaciones. 


\section{BIBLIOGRAFÍA}

ALMAGRO GORBEA, María Josefa; ALONSO CEREZA, Eduardo (2009): Vidrios antiguos del Museo Nacional de Artes Decorativas. Real Academia de la Historia.

BERNUS-TAYLOR, Marthe (2000): "Le verre dans les collections islamiques du Louvre", El vidrio en al-Andalus. Palermo, Casa de Velázquez y Fundación Centro Nacional del Vidrio, pp. 43-61.

CAPELLÀ, Miquel Ángel; María. Magdalena RIERA (2015): "El vidrio de época andalusí: problemática y bases para su estudio en las Baleares", VI Jornades d'Arqueologia de les Illes Balears. Formentera, Consell Insular de Formentera, pp. 313-321.

CASTILLO Francisco; MARTINEZ, Rafael (2000): "Un taller de vidrio en Baŷȳāna-Pechina (Almería)", El vidrio en alAndalus. Palermo, Casa de Velázquez y Fundación Centro Nacional del Vidrio, pp. 83-101.

CARMONA, Noemí; GARCÍA-HERAS, Manuel; VILLEGAS, María Ángeles (2008): "Study of chromophores of islamic glasses from al-Andalus (Murcia, Spain)", Lasers in the conservation of Artworks. London, pp. 73-78. https://doi. org/10.1016/j.culher.2008.12.005

CARMONA, Noemí; VILLEGAS, María Ángeles; JIMÉNEZ, Pedro; NAVARRO, Julio; GARCÍA-HERAS, Manuel (2009): "Islamic glasses from Al-Andalus. Characterisation of materials from a Murcian workshop", Journal of Cultural Heritage, 10, pp. 439-445. Disponible en: http://www.sciencedirect.com/science/article/pii/ S1296207409000569 [Consulta: 25 de abril de 2016].

CARBONI, Stefano. (2001): "Archaeological excavations of Islamic Glass”, Glass of the Sultans. Nueva York, pp. 14-24.

COLL RIERA, Juan Manuel. (2004): "Los vidrios de la antigüedad tardía de la Iglesia vieja de Sant Menna (Barcelona)", El vidrio en la España Romana. Fundación Centro Nacional del Vidrio, pp. 449-454.

CRESSIER, Patrice (Ed.) (2000): El vidrio en al-Andalus, Palermo, Casa de Velázquez-Fundación Centro Nacional del Vidrio.

DE JUAN ARES, Jorge. (2000): "La alcazaba de Vascos: Aproximación a su evolución y características", Entre el Califato y la Taifa. Mil años del Cristo de la Luz. Toledo, Asociación de Amigos del Toledo Islámico, pp. 307-315. Disponible en: https://www. academia.edu/4630734/_La_alcazaba_de_Vascos_ aproximaci\%C3\%B3n_a_su_evoluci\%C3\%B3n_y_ caracter\%C3\%ADsticas_._Congreso_Internacional. Entre_el_Califato_y_la_Taifa. Mil_a\%C3\%B1os del Cristo_de_la_Luz_Toledo_1999_307-314 [Consulta: 25 de abril de 2016].

DE JUAN ARES, Jorge (2005): "Las alcazabas: fortalezas urbanas de al-Andalus", II Congreso de Castellología Ibérica. Madrid,Asociación Española de Castellología, pp. 433-443.

DE JUAN ARES, Jorge (2016): Análisis arqueológico de un centro de poder: la alcazaba de Ciudad de Vascos. Tesis doctoral, Universidad Complutense de Madrid. Disponible en: http://eprints.ucm.es/39542/ [Consulta: 25 de abril de 2016].
DE JUAN, Jorge; CÁCERES, Yasmina (2010): "La mezquita de la alcazaba de Vascos", Monográficos del Consorcio. No V. Toledo, pp. 335-350. Disponible en: https://www.academia.edu/4771463/_La_mezquita_ de_la_Alcazaba_de_Ciudad_de_Vascos_. Mezquitas_de_Toledo_a_la_luz_de_los_nuevos_descubrimientos. Monogr\%C3\%Alficos Consorcio de Toledo_5_2010_335-349 [Consulta: 25 de abril de 2016].

DE JUAN, Jorge; CÁCERES, Yasmina (en prensa): Fichas catalográficas del vidrio de la exposición Al-Mariyya. Puerta de Oriente. Almería, Museo de Almería, 2015.

DUCKWORTH, Chloë; CÓRDOBA, Ricardo; FABER, Edward; GOVANTES EDWARDS; David; HENDERSON, Julian (2015): "Electron Microprobe Analysis of 9th-12th Century Islamic Glass from Cordoba, Spain", Archaeometry 57 (1). Oxford, pp. 27-50. Disponible en: http://onlinelibrary. wiley.com/doi/10.1111/arcm.12079/abstract [Consulta: 25 de abril de 2016].

FERNANDEZ NAVARRO, José María. (1991): El vidrio. CSIC. Fundación Centro Nacional del Vidrio. Segovia.

FOY, Danielle (2000): "Les indices d'une production de verre: reperages et interpretations", El vidrio en alAndalus. Palermo, Casa de Velázquez y Fundación Centro Nacional del Vidrio, pp. 13-41.

GAMO PARRAS, Blanca (1995): "Vidrios de época visigoda en España. Una aproximación", Le Verre de l'antiquite tardive et du Haut Moyen Age. París, CNRS, pp. 301-317.

GAMO PARRAS, Blanca (2010): "Un material frágil y olvidado. El estudio del vidrio de época visigoda en Hispania", Zona Arqueológica. № 11. Madrid, Museo Arqueológico Regional, pp. 477-487.

GARCÍA GOMEZ, Emilio; LEVÍ-PROVENÇAL, Evariste (1981): Sevilla a comienzos del siglo XII. El tratado de Ibn Abdum, Sevilla. Colegio Oficial de Aparejadores y Arquitectos Técnicos.

GARCÍA SANDOVAL, Juan (2009): "El resplandor de las Lámparas de vidrio de la Sinagoga de Lorca. Estudio Tipológico", Luces de Sefarad. Lorca, Tres fronteras.

GOMEZ-MORENO, Manuel. (1951): "El arte árabe españo hasta los almohades. Arte mozárabe”. Ars Hispaniae, III. Madrid, Plus-Ultra.

GONZALEZ PASCUAL, Margarita (2014): "La puesta en valor de un conjunto de fragmentos de arco decorados con yeserías islámicas hallado en el antiguo convento de Santa Fe de Toledo", Informes y Trabajos. № 10, Madrid, Instituto del Patrimonio Cultural de España, pp. 195-226. Disponible en: http://ipce.mcu.es/difusion/publicaciones/revistas-inf.html [Consulta: 25 de abril de 2016].

GUTIERREZ LLORET, Sonia (1996): La Cora de Tudmir de la antigüedad tardía al mundo islámico. Población y cultura material. Collection de la Casa de Velázquez № 57. Madrid, Casa de Velázquez.

GRATUZE, Bernard; GUERIT, Magalie; SIMON, Laure; VILLAVERDE, Laurent; BARBIER Emmanuel (2014): "Des verres carolingiens de composition atypique à Bressuire et Faye-sur-Ardin (nord de la région melloise, Deux-Sèvres)", Bulletin de l'Association française pour l'archéologie du verre, París, AFAV, pp. 114-120. 
ISINGS, Clasina. (1957): Roman Glass from dated finds. Archaeologica Traiectina II, Groningen-Yakarta.

IZQUIERDO BENITO, Ricardo (1983): "Ciudad Hispanomusulmana "Vascos", Navalmoralejo, Toledo, Campañas 1979-80", Noticiario Arqueológico Hispánico. № 16, Madrid, Ministerio de Cultura, pp. 289-380. Disponible en: http://www.ciudaddevascos.com/Publicaciones/1983\%20Noticiario\%20Arqueol\%C3\%B3gico\%20 Hisp\%C3\%Alnico.pdf

IZQUIERDO BENITO, Ricardo (1986): "Los baños árabes de Vascos (Navalmoralejo, Toledo). Noticiario Arqueológico Hispánico. № 28, Madrid, Ministerio de Cultura, pp. 193-242. Disponible en: http://www.ciudaddevascos.com/Publicaciones/1986\%20Noticiario\%20 Arqueol\%C3\%B3gico\%20Hisp\%C3\%Alnico.pdf

IZQUIERDO BENITO, Ricardo (1994): Ciudad Hispanomusulmana "Vascos", Navalmoralejo, Toledo, Campañas 1983-1988. Toledo, Servicio de Publicaciones de CastillaLa Mancha. Disponible en: http://www.ciudaddevascos. com/Publicaciones/1994\%20Ciudad\%20Hispanomusulmana\%20VASCOS\%20Campa\%C3\%B1as\%20\%288388\%29.pdf

IZQUIERDO BENITO, Ricardo (1996): "Unas tenerías excavadas en la Ciudad Hispanomusulmana de Vascos", Arqueología y territorio Medieval. № 3, Jaén, Universidad de Jaén, pp. 149-165. Disponible en: http://revistaselectronicas.ujaen.es/index.php/ATM/article/view/1627

IZQUIERDO BENITO, Ricardo (1999): Vascos: La vida cotidiana en una ciudad fronteriza de Al-Andalus. Colección "Imágenes y palabras". № 28, Toledo, Junta de Comunidades de Castilla la Mancha.

IZQUIERDO BENITO, Ricardo (2008): "La alcazaba de Vascos”, Castrum. No 8, Madrid, Casa de Velazquez-École francaise de Rome, pp. 269-281. Disponible en: http:// www.ciudaddevascos.com/Publicaciones/2008\%20 Castrum\%208.\%20Alcazaba\%20Vascos.pdf

IZQUIERDO BENITO, Ricardo; DE JUAN ARES, Jorge (2003): "Excavaciones en la alcazaba de Vascos (Navalmoralejo, Toledo)". Investigaciones arqueológicas en Castilla-La Mancha, 1996-2002. Toledo, Junta de Comunidades de Castilla-La Mancha, pp. 423-436. Disponible en: http:// www.ciudaddevascos.com/Publicaciones/1995\%20 Investigaciones\%20arqueol\%C3\%B3gicas\%20de\%20 CLM.pdf

IZQUIERDO BENITO, Ricardo; DE JUAN ARES, Jorge (2007): "Un edificio significativo excavado en la ciudad hispanomusulmana de Vascos (Toledo)", Arqueología de Castilla-La Mancha. Cuenca, Universidad de CastillaLa Mancha, pp. 755-774. Disponible en: http://www. ciudaddevascos.com/Publicaciones/2007\%20un\%20 edificio\%20significativo.pdf

IZQUIERDO BENITO, Ricardo; PRIETO VAZQUEZ, Germán (1993-94): "Una pequeña mezquita encontrada en Vascos", Cuadernos de la Alambra. № 29-30, Granada, Patronato de la Alhambra y Generalife pp. 21-38. Disponible en: http://www.ciudaddevascos.com/Publicaciones/1993-\%201994\%20Cuadernos\%20de\%20la\%20 Alhambra.\%20Pequea\%20Mezquita.pdf
JIMENEZ CASTILLO, Pedro (1993): "El vidrio". Una casa islámica en Murcia. Estudio de su ajuar (siglo XIII). Murcia, Centro de Estudios árabes y arqueológicos "Ibn Arabi", Ayuntamiento de Murcia, pp. 71- 80.

JIMENEZ CASTILLO, Pedro (2000): F "El vidrio andalusí en Murcia”, El vidrio en al-Andalus. Palermo, Casa de Velázquez y Fundación Centro Nacional del Vidrio, pp. 117-148.

JIMENEZ CASTILLO, Pedro (2006): "Talleres, técnicas y producciones del vidrio en al-Andalus”. Vidrio islámico en al-Andalus, Real Fábrica de Cristales de La Granja, Fundación Centro Nacional del Vidrio, pp. 51-80.

MARTíNEZ SALVADOR, Carmen; BELLÓN AGUILERA, Jesús (2005): "Consideraciones sobre la simbología, tradición y materialidad del vino en al-Andalus", Revista Murciana de Antropología. № 12, Murcia, Universidad de Murcia, pp. 159-174. Disponible en: http://revistas.um.es/rmu/ article/view/68161/65631 [Consulta: 25 de abril de 2016].

MONZÓN, Fabiola; MARTín, Concepción (2006): "El antiguo convento de Santa Fe de Toledo. Recuperación de algunas dependencias de época musulmana", Bienes Culturales. No 6, Madrid, Instituto del Patrimonio Cultural de España, pp. 53-76. Disponible en: http://eu.www.mcu. es/patrimonio/docs/MC/IPHE/BienesCulturales/N6/06antiguo_convento.pdf [Consulta: 25 de abril de 2016].

NAVARRO PALAZON, Julio; ROBLES FERNANDEZ, Alfonso (1996): Lietor. Formas de vida rurales en Shara al -Andalus a través de una ocultación de los siglos X-XI. Murcia. Centro de Estudios Árabes y Arqueológicos "Ibn Arabi", Ayuntamiento de Murcia.

NAVARRO, Julio; JIMÉNEZ, Pedro (2002): "Religiosidad y creencias en la Murcia musulmana: testimonios arqueológicos de una cultura oriental", Huellas. Murcia, Caja de Ahorros de Murcia, pp. 58-87. Disponible en: < http:// digital.csic.es/handle/10261/13358?mode=full\&locale= es>. [Consulta: 25 de abril de 2016].

NAVARRO, Julio; JIMÉNEZ, Pedro (2009): «Talisman de yeso», en Alfonso X y su época. Catalogo de exposición. Murcia, Región de Murcia, pp. 482. Disponible en <http:// digital.csic.es/handle/10261/19569>. [Consulta: 25 de abril de 2016].

PÉREZ-ARANTEGUI, Josefina (2015): "Pigmentos, colorantes, resinas,... o qué nos cuenta el contenido de los objetos de la vida cotidiana", De las ánforas al museo. Estudios dedicados a Miguel Beltrán Lloris. Zaragoza, Institución Fernando el Católico, pp. 713-724. Disponible en <http://ifc.dpz.es/recursos/publicaciones/35/21/4 9perezarantegui.pdf>. [Consulta: 25 de abril de 2016].

PUCHE ACIEN, Catalina. 1993: "El vidrio de época almohade en la Península Ibérica: primera aproximación formal", Congreso de Arqueología Medieval. No IV, Vol. III, Alicante, Asociación Española de Arqueología MedievalDiputación de Alicante, pp. 927-936.

PUCHE ACIEN, Catalina. (2000): "Los vidrios islámicos de Alicante", El vidrio en al-Andalus. Palermo, Casa de Velázquez y Fundación Centro Nacional del Vidrio, pp. 149-164. 
RONTOME NOTARIO, Enrique (2000): "Vidrios califales de Madīnat al-Zahrā'”, El vidrio en al-Andalus. Palermo, Casa de Velázquez y Fundación Centro Nacional del Vidrio, pp. 103-115.

RONTOME NOTARIO, Enrique; PASTOR REY, Paloma (Eds.) (2006): Vidrio islámico en al-Andalus. La Granja, Rea Fábrica de Cristales de La Granja, Fundación Centro Nacional del Vidrio.

RUIZ MOLINA, Liborio. (2000): «Hisn Yakka. Un castillo rural de Sarq Al-Andalus. Siglos XI al XIII. Excavaciones Arqueológicas en el Cerro del Castillo de Yecla (19901999)», Yakka. № 10, Yecla, Museo Arqueológico de Yecla. Número monográfico. Disponible en: <http://recursosmaye.blogspot.com.es/p/yakka-n-10.html >. [Consulta: 25 de abril de 2016]

SALINAS PLEGUEZUELO, María Elena (2003): El vidrio romano de Córdoba, Arqueología Cordobesa. No 8 , Córdoba, Servicio de Publicaciones de la Universidad de Córdoba.
Andrew; SCHACHNER, Lukas; FREESTONE, Ian; TITE, Michael (2006): "Natron as a flux in the early vitreous materials industry: sources, beginnings and reasons for decline", Journal of Archaeological Science. Vol 33, Elsevier, pp. 521-530. Disponible en: http://www.sciencedirect.com/science/article/pii/S0305440305002074 [Consulta: 25 de abril de 2016].

TORRECILLA AZNAR, Ana (2004): "Los vidrios romanos de la Villa de El Saucedo (Talavera la Nueva, Toledo). El vidrio en la España Romana. La Granja, Fundación Centro Nacional del Vidrio, pp. 323-349.

VARELA GOMES, Rosa (2003): "Silves (Xelb), uma cidade do Gharb Al-Andalus. A Alcáçova”, Trabalhos de Arqueologia. № 35, Lisboa, Direção-Geral do Patrimonio Cultural.

ZOZAYA, Juan (2000): "Algunas sugerencias sobre el estudio de vidrio en Al-Andalus", El vidrio en al-Andalus. Palermo, Casa de Velázquez y Fundación Centro Nacional del Vidrio, 2000, pp. 63-81. 